\title{
Condições meteorológicas e tipo de solo na composição da uva 'Cabernet Sauvignon'
}

\author{
Rodrigo Vieira Luciano(1), Jackson Adriano Albuquerque(1), Leo Rufato(1), David José Miquelluti(1) \\ e Maria Tereza Warmling(1)
}

\begin{abstract}
(1) Universidade do Estado de Santa Catarina, Departamentos de Solos, Recursos Naturais e Agronomia, Centro de Ciências Agroveterinárias, Campus Universitário, Bairro Conta Dinheiro, Caixa Postal 281, CEP 88520-000 Lages, SC. E-mail: agro.luciano@gmail.com, albuquerque@pq.cnpq.br, leoruffato@yahoo.com.br, a2djm@cav.udesc.br, tetecav@yahoo.com.br
\end{abstract}

\begin{abstract}
Resumo - O objetivo deste trabalho foi avaliar os efeitos das condições meteorológicas e do tipo de solo sobre características físico-químicas e compostos fenólicos da uva 'Cabernet Sauvignon' (Vitis vinifera). O experimento foi realizado em vinhedo implantado em 2003, enxertado sobre o porta-enxerto 'Paulsen 1103' e conduzido no sistema espaldeira. No vinhedo, foram selecionados dois solos: Cambissolo Háplico e Cambissolo Húmico. O efeito das condições meteorológicas (precipitação e temperatura mínima e máxima do ar) foi avaliado nas safras 2008/2009, 2009/2010 e 2010/2011. Foram determinados os atributos físicos e químicos dos solos, os teores de sólidos solúveis, a acidez titulável e o $\mathrm{pH}$ do mosto, bem como o índice de polifenóis totais e dos teores de antocianinas e de taninos da uva. Os fatores solo e as condições meteorológicas (safras) foram arranjados em esquema fatorial $2 \times 3$. Com exceção do teor de polifenóis totais, as condições meteorológicas e o tipo de solo afetam as características físico-químicas da uva 'Cabernet Sauvignon', com efeito mais pronunciado das condições meteorológicas do que do tipo de solo. Menores precipitações e maiores amplitudes térmicas favorecem o acúmulo de sólidos solúveis na uva 'Cabernet Sauvignon'. Maiores precipitações favorecem o aumento da acidez do mosto.
\end{abstract}

Termos para indexação: Vitis vinifera, compostos fenólicos, disponibilidade de água, fertilidade do solo, taninos, "terroir".

\section{Weather and soil effects on the composition of 'Cabernet Sauvignon' grape}

\begin{abstract}
The objective of this work was to evaluate the effects of weather and soil type on the physicochemical characteristics and phenolic compounds of the 'Cabernet Sauvignon' grape (Vitis vinifera). The experiment was carried out in a vineyard established in 2003, grafted onto 'Paulsen 1103', and conducted in the cordon system. Two soils were selected in the vineyard: Typic Dystrudepts and Pachic Humudepts. The effect of weather (rainfall, and minimum and maximum temperature) was evaluated in the seasons 2008/2009, 2009/2010, and 2010/2011. Soil physical and chemical properties, soluble solids, titratable acidity and $\mathrm{pH}$ of the wort were determined, as well as the index of total polyphenols, and anthocyanin and tannin contents of the grape. The factors soil and meteorological conditions (crop seasons) were arranged in a $2 \times 3$ factorial. Except for the total polyphenol content, weather and soil type affect the physicochemical characteristics of 'Cabernet Sauvignon'. The effect of weather is more pronounced than the effect of soil type. Lower rainfall and higher temperature ranges favor the accumulation of soluble solids in the 'Cabernet Sauvignon' grape. Higher rainfall favors the increase of wine acidity.
\end{abstract}

Index Terms: Vitis vinifera, phenolic compounds, water availability, soil fertility, tannins, terroir.

\section{Introdução}

A composição da uva é definida pela interação entre clima, solo, cultivar (variedade e porta-enxerto) e práticas culturais que, associados, definem o "terroir" de uma determinada região vinícola (Leeuwen et al., 2004; Zsófi et al., 2009). O tipo de solo e as práticas vitivinícolas não mudam significativamente de um ano para o outro; entretanto, as condições meteorológicas podem mudar e afetar a composição da uva (Downey et al., 2006). Assim, a variabilidade climática comumente é o fator com efeito determinante no "terroir", em uma mesma região vinícola (Leeuwen \& Seguin, 2006). Pesquisas indicam efeitos importantes da temperatura diária do ar e da temperatura noturna mínima (Deloire et al., 2005), na acumulação de compostos fenólicos e na cor da uva, especialmente durante a maturação (Downey et al., 2006). 
Temperatura diurna elevada, durante o período de maturação, diminui o teor de antocianinas (Leeuwen et al., 2004).

A disponibilidade de água às plantas é dependente dos atributos do solo e da demanda pela cultura. Solos com classe textural franca, normalmente, têm maior potencial para o desenvolvimento radicular das videiras (Kuhn, 2003) e boa capacidade de retenção de água disponível às plantas (Reichert et al., 2009). Os solos com maior profundidade efetiva, desde que não tenham limitações químicas, são os que têm o maior potencial para o desenvolvimento radicular da videira e os com menor possibilidade de sofrer estresse hídrico. O excesso de água, em solos com baixa drenagem, prejudica a qualidade da uva (Chavarria et al., 2011).

Geralmente, o deficit hídrico leve a moderado tem efeito positivo na composição da uva, por favorecer o acúmulo de compostos fenólicos (antocianinas e taninos) (Castellarin et al., 2007) e, consequentemente, a qualidade do vinho (Zsófi et al., 2011). A disponibilidade de água no solo modifica a concentração de açúcar na uva. Em solos com menor disponibilidade de água, o crescimento vegetativo e o consumo de carboidratos pela parte aérea são menores, e a quantidade de carboidratos disponíveis para as bagas é maior (Lebon et al., 2006). A menor disponibilidade de água no solo também favorece o amadurecimento da uva e diminui o tamanho das bagas. Porém, em solos com maior disponibilidade de água, o tamanho das bagas é maior, e o teor de açúcar nas bagas é menor, pois ocorre competição dos carboibrados entre as bagas e a parte aérea (Leeuwen et al., 2009). Portanto, a concentração de açúcar na baga depende da cultivar (Borghezan et al., 2011), do solo e do clima (Lebon et al., 2006; Leeuwen et al., 2009).

Ao estudar três tipos de solos cultivados com as variedades Merlot, Cabernet Sauvignon e Cabernet Franc, Leeuwen et al. (2009) observaram maior concentração de açúcar e de antocianinas na baga, em condição de deficit hídrico leve. Ubalde et al. (2010) observaram efeito da precipitação pluviométrica e das temperaturas diárias nos compostos fenólicos da uva (antocianinas e taninos), em estudo com dois tipos de solo, cultivados com 'Cabernet Sauvignon'. Morlat \& Bodin (2006) observaram efeito do solo no teor de antocianinas, e do solo e do clima no índice de polifenóis totais, na variedade Cabernet Franc. Chavarria et al. (2011) observaram que o deficit hídrico aumentou o índice de polifenóis totais e os teores de taninos nas bagas da uva 'Cabernet Sauvignon', em três tipos de solos no Brasil.

Borghezan et al. (2011) relacionaram a menor precipitação pluviométrica e a maior amplitude térmica, à composição da uva e ao comportamento vegetativo e produtivo de variedades de videira Cabernet Sauvignon. No entanto, estudos desta natureza são escassos no Brasil, ainda mais com a avaliação também do efeito do solo sobre essas características.

O objetivo deste trabalho foi determinar os efeitos das condições meteorológicas e do tipo de solo sobre as características físico-químicas e os compostos fenólicos da uva 'Cabernet Sauvignon'.

\section{Material e Métodos}

O experimento foi realizado em vinhedo com a variedade Cabernet Sauvignon (Vitis vinifera L.), implantado em 2003, enxertada sobre o porta-enxerto 'Paulsen 1103' (Vitis berlandieri x Vitis rupestris), no sistema de condução espaldeira. O vinhedo está localizado no Planalto Catarinense, no Município de São Joaquim $\left(28^{\circ} 15^{\prime} 32^{\prime \prime} \mathrm{S}, 4^{\circ} 57^{\prime} 35^{\prime \prime} \mathrm{W}\right)$ à altitude média de $1.260 \mathrm{~m}$. O clima do local, segundo a classificação de Köppen, é do tipo $\mathrm{Cfb}$, mesotérmico, úmido, sem estação seca, com verão fresco $\left(<22^{\circ} \mathrm{C}\right)$. A média da temperatura máxima varia de 19,4 a $22,3^{\circ} \mathrm{C}$, e a da temperatura mínima de 9,2 a $10,8^{\circ} \mathrm{C}$. A precipitação pluvial anual varia de 1.360 a $1.600 \mathrm{~mm}$, o total anual de dias de chuva é de 135 , e a umidade relativa do ar varia de 80 a $83 \%$, com insolação anual total de 1.824 a 2.083 horas (Benez et al., 2002). Os solos avaliados foram classificados, conforme Santos et al. (2006), como Cambissolo Húmico alumínico típico (Pachic Humudepts) e Cambissolo Háplico alítico típico (Typic Dystrudepts), desenvolvidos a partir de riodacito (Tabela 1).

Até abril de 2000, as glebas do estudo foram mantidas com campo natural. Nesse ano, as áreas foram preparadas com aração a $30 \mathrm{~cm}$ de profundidade, e a acidez foi corrigida com a aplicação de $25 \mathrm{Mg} \mathrm{ha}^{-1}$ de calcário dolomítico (PRNT a 100\%), para obtenção de pH 6,0. Na adubação de implantação, foram aplicados $450 \mathrm{~kg} \mathrm{ha}^{-1}$ de superfosfato triplo e $300 \mathrm{~kg} \mathrm{ha}^{-1} \mathrm{de}$ cloreto de potássio. A adubação de cobertura seguiu as recomendações do manual da Comissão de Química e Fertilidade do Solo (CQFS - RS/SC, 2004), com reposição de fósforo e potássio. As mudas foram 
plantadas no espaçamento de $1,2 \mathrm{~m}$ entre plantas e 3,0 $\mathrm{m}$ entre as filas, orientadas no sentido norte-sul, conduzidas no sistema espaldeira, com cobertura antigranizo. A área avaliada de cada solo foi de $3.456 \mathrm{~m}^{2}$, onde foram cultivadas 930 plantas.

Para cada solo, foi demarcada uma malha composta de cinco linhas de plantio com sete pontos de amostragem por linha, espaçados em $12 \mathrm{~m}$, o que resultou em um retângulo de $48 \times 72 \mathrm{~m}\left(3.456 \mathrm{~m}^{2}\right)$, além de dois pontos no centro da área, no total de 37 pontos. Em cada ponto, foram selecionadas e avaliadas três plantas. Assim, para cada solo, foram amostradas 111 plantas. De cada planta, foi coletado sempre o primeiro cacho do ramo do ano, tendo-se padronizado a posição do cacho na planta.

Os dados diários de precipitação e temperaturas mínima, média e máxima foram fornecidos pelo Centro de Informações de Recursos Ambientais e de Hidrometeorologia de Santa Catarina (Ciran), obtidos de estação meteorológica automática (São Joaquim Inmet 1512), localizada na estação experimental da Empresa de Pesquisa Agropecuária e Extensão Rural de Santa Catarina, a $1.000 \mathrm{~m}$ de altitude e $2.900 \mathrm{~m}$ de distância da área experimental.

Os dados mensais de armazenamento de água nos solos foram obtidos quinzenalmente, ao longo do ciclo reprodutivo da videira, nas safras de 2008/2009 e 2009/2010, por Luciano (2012), e calculados segundo Reichardt (1985).

Foram realizadas colheitas em três safras, em 14/4/2009, 30/3/2010 e 16/4/2011, na fase de maturação industrial. Para analisar os atributos físico-químicos e os componentes fenólicos da uva, foi colhido um cacho por planta selecionado para ser representativo quanto à sanidade, tamanho e posição na planta. Os cachos foram acondicionados individualmente, em sacos plásticos, que foram dispostos em caixas de plástico e transportados até o laboratório.

Dos três cachos de uva coletados em cada ponto, foram separadas 50 bagas, para determinar a concentração dos compostos fenólicos. As demais bagas foram esmagadas manualmente, tendo-se extraído o mosto com coador de tecido de algodão, para determinar os atributos físico-químicos da uva.

O teor de sólidos solúveis (SS) foi determinado com um refratômetro óptico; a acidez titulável (AT) foi determinada por meio da titulação com solução alcalina padronizada de $\mathrm{NaOH} 0,1 \mathrm{~N}$ e com o indicador azul de bromotimol; o potencial hidrogeniônico $(\mathrm{pH})$ foi medido com um potenciômetro digital (Amerine et al., 1976).

Utilizou-se solução hidroalcoólica, com etanol a 50\% (v.v), $\mathrm{pH}$ 2,0, para simular a extração das antocianinas e polifenóis totais durante a fermentação alcoólica da vinificação, segundo Iland et al. (2004). A quantificação das antocianinas extraíveis e do aporte de taninos às bagas foram realizadas segundo Ribereau-Gayon et al. (1998).

No solo, foram realizadas coletas de amostras com estrutura deformada, em cada um dos pontos da malha, na camada $0-30 \mathrm{~cm}$, com o uso de um trado calador, para a determinação dos atributos químicos do solo $\mathrm{P}$, K, Ca e Mg (Tedesco et al., 1995).

Os resultados foram analisados com o modelo linear de análise de variância, aplicado a experimento em delineamento inteiramente casualizado, com arranjo fatorial $2 \times 3$ (solos $\mathrm{x}$ condições meteorológicas (safras)). Os dados foram testados, quanto à normalidade, pelo teste de Shapiro-Wilk. As variáveis dependentes foram as relacionadas à composição da uva, e as independentes foram o tipo de solo e as condições meteorológicas (safras). $\mathrm{O}$ efeito das condições meteorológicas engloba a precipitação pluviométrica e as temperaturas mínima, média e máxima diárias. As médias foram comparadas pelo teste DMS de Fisher. A correlação de Pearson entre características fisico-químicas e compostos fenólicos da uva foi avaliada. Determinou-se, também, a correlação entre compostos fenólicos da uva e os atributos químicos do solo, $\mathrm{Ca}, \mathrm{K}$ e $\mathrm{Mg}$. Foram obtidas as percentagens de variação dos efeitos principais e de interação no modelo, a partir

Tabela 1. Caracterização química e granulométrica dos solos avaliados, na camada de 0-30 cm.

\begin{tabular}{|c|c|c|c|c|c|c|c|c|c|c|c|c|c|c|c|}
\hline \multirow{2}{*}{ Solo $^{(1)}$} & \multicolumn{2}{|c|}{$\mathrm{pH}$} & $\mathrm{P}$ & $\mathrm{K}$ & $\mathrm{Na}$ & $\mathrm{H}+\mathrm{Al}$ & $\mathrm{Al}$ & $\mathrm{Ca}$ & $\mathrm{Mg}$ & & \multirow[t]{2}{*}{ Areia fina } & \multirow[t]{2}{*}{ Areia grossa } & \multirow[t]{2}{*}{ Silte } & \multirow[t]{2}{*}{ Argila } & \multirow{2}{*}{$\begin{array}{c}\text { Classe } \\
\text { textural }^{(2)}\end{array}$} \\
\hline & Água & $\mathrm{CaCl}_{2}$ & ------- & $\left.\mathrm{kg}^{-1}\right)$ & ----- & & $(\mathrm{cmo}$ & $\left.\mathrm{kg}^{-1}\right)$ & ----- & & & & & & \\
\hline $\mathrm{H}$ & 6,3 & 5,6 & 9,1 & 56 & 15 & 9,6 & 0,5 & 7,7 & 2,1 & 90 & 32 & 73 & 627 & 268 & FS \\
\hline CX & 6,9 & 6,3 & 4,5 & 60 & 9 & 2,0 & 0,4 & 5,9 & 1,5 & 33 & 54 & 136 & 447 & 363 & FAS \\
\hline
\end{tabular}

${ }^{(1)} \mathrm{CH}$, Cambissolo Húmico; CX, Cambissolo Háplico. ${ }^{(2)} \mathrm{FS}$, franco-siltoso; FAS, franco-argilo-siltoso 
da divisão da soma de quadrados de cada componente pelo total, multiplicado por 100 . Em todas as análises, foi adotado o nível de significância de 5\%, e foram expressos apenas os resultados significativos. O programa utilizado foi o Assistat.

\section{Resultados e Discussão}

A precipitação anual foi elevada nos três anos de condução do experimento, maior do que a precipitação média dos últimos 10 anos, de $1.907 \mathrm{~mm}$ (Ciram-Epagri-2011) (Tabela 2). A temperatura média anual foi de $12,9^{\circ} \mathrm{C}$ em $2008,13,7^{\circ} \mathrm{C}$ em $2009,13,4^{\circ} \mathrm{C}$ em 2010 e $13,1^{\circ} \mathrm{C}$ em 2011, semelhante à média dos últimos 10 anos, de $13,6^{\circ} \mathrm{C}$.

Do período de brotação até a mudança na coloração das bagas (setembro a fevereiro), e no período de maturação da uva (março a abril), a precipitação foi mais elevada na safra de 2009/2010. No período de dezembro a fevereiro, na safra 2009/2010 ocorreram as mais altas temperaturas. Contudo, na safra 2008/2009, as mais altas temperaturas (Tabela 2) ocorreram no período da colheita (março a abril). A temperatura (mínima e máxima) seguiu a mesma tendência dos últimos 10 anos, com aumento gradativo de dezembro a janeiro/fevereiro, e redução durante o período da colheita (março/abril). Essa diminuição da temperatura no período de março/abril, associada à menor precipitação observada nas safras de 2008/2009 e 2010/2011, no período da colheita da uva, favorece a maturação fenológica completa da uva (Borghezan et al., 2011), condições não observadas na safra de 2009/2010, que apresentou maior precipitação.

$\mathrm{O}$ armazenamento médio de água no solo foi maior no Cambissolo Húmico, em comparação ao Cambissolo Háplico, nos meses de dezembro, janeiro e março, na safra 2008/2009, e em todos os meses avaliados na safra 2009/2010 (Tabela 3). O elevado teor de

Tabela 2. Precipitação e temperaturas mínima e máxima quinzenais ( $1^{\mathrm{a}}$ e $2^{\mathrm{a}}$ quinzenas), no período reprodutivo da videira 'Cabernet Sauvignon' nas safras 2008/2009, 2009/2010 e 2010/2011.

\begin{tabular}{|c|c|c|c|c|c|c|c|c|c|c|c|c|}
\hline \multirow[t]{2}{*}{ Safra } & \multicolumn{2}{|c|}{ Dezembro } & \multicolumn{2}{|c|}{ Janeiro } & \multicolumn{2}{|c|}{ Fevereiro } & \multicolumn{2}{|c|}{ Março } & \multicolumn{2}{|c|}{ Abril } & \multirow{2}{*}{$\begin{array}{c}\text { Dezembro } \\
\text { a abril }\end{array}$} & \multirow[t]{2}{*}{ Anual } \\
\hline & $1^{\mathrm{a}}$ & $2^{\mathrm{a}}$ & $1^{\mathrm{a}}$ & $2^{\mathrm{a}}$ & $1^{\mathrm{a}}$ & $2^{\mathrm{a}}$ & $1^{\mathrm{a}}$ & $2^{a}$ & $1^{\mathrm{a}}$ & $2^{a}$ & & \\
\hline & \multicolumn{12}{|c|}{ Precipitação pluviométrica (mm) } \\
\hline $2008 / 2009$ & 57,3 & 35,3 & 125,3 & 66,9 & 18,7 & 91,8 & 82,0 & 11,1 & 0,0 & 23,8 & 512,2 & $2.028,0$ \\
\hline $2009 / 2010$ & 73,1 & 71,6 & 200,2 & 171,7 & 189,1 & 115,5 & 80,0 & 98,3 & 24,7 & 205,0 & $1.229,2$ & $2.545,0$ \\
\hline \multirow[t]{2}{*}{$2010 / 2011$} & 91,5 & 75,3 & 32,3 & 163,0 & 150,3 & 213,1 & 19,6 & 170,0 & 59,8 & 57,6 & $1.032,5$ & $2.261,0$ \\
\hline & \multicolumn{12}{|c|}{ Temperatura mínima $\left({ }^{\circ} \mathrm{C}\right)$} \\
\hline $2008 / 2009$ & 10,4 & 11,8 & 12,2 & 12,6 & 13,4 & 14,8 & 14,4 & 12,8 & 11,3 & 10,0 & 12,4 & 10,1 \\
\hline $2009 / 2010$ & 11,8 & 14,9 & 14,8 & 14,3 & 17,0 & 13,7 & 12,9 & 13,5 & 12,9 & 13,5 & 13,4 & 9,9 \\
\hline \multirow[t]{2}{*}{$2010 / 2011$} & 11,2 & 13,2 & 14,1 & 15,8 & 14,9 & 14,4 & 11,7 & 12,0 & 10,1 & 11,3 & 12,9 & 9,5 \\
\hline & \multicolumn{12}{|c|}{ Temperatura máxima $\left({ }^{\circ} \mathrm{C}\right)$} \\
\hline $2008 / 2009$ & 19,9 & 22,9 & 20,3 & 21,6 & 23,2 & 22,2 & 22,6 & 22,3 & 21,4 & 19,0 & 21,5 & 19,0 \\
\hline $2009 / 2010$ & 21,5 & 24,3 & 22,8 & 22,4 & 25,2 & 22,5 & 21,5 & 21,3 & 21,5 & 21,3 & 21,7 & 18,4 \\
\hline $2010 / 2011$ & 20,2 & 22,9 & 23,4 & 24,0 & 22,5 & 21,9 & 20,8 & 20,8 & 19,3 & 19,4 & 21,5 & 18,3 \\
\hline
\end{tabular}

Fonte: Empresa de Pesquisa Agropecuária e Extensão Rural de Santa Catarina (2011).

Tabela 3. Armazenamento de água $(\mathrm{mm})$ nos solos avaliados, em avaliações quinzenais $\left(1^{\mathrm{a}}\right.$ e $2^{\mathrm{a}}$ quinzenas) nas safras $2008 / 2009$ e $2009 / 2010^{(1)}$.

\begin{tabular}{|c|c|c|c|c|c|c|c|c|c|c|}
\hline \multirow[t]{2}{*}{ Solo } & \multicolumn{2}{|c|}{ Dezembro } & \multicolumn{2}{|c|}{ Janeiro } & \multicolumn{2}{|c|}{ Fevereiro } & \multicolumn{2}{|c|}{ Março } & \multicolumn{2}{|c|}{ Abril } \\
\hline & $1^{\mathrm{a}}$ & $2^{\mathrm{a}}$ & $1^{\mathrm{a}}$ & $2^{\mathrm{a}}$ & $1^{\mathrm{a}}$ & $2^{\mathrm{a}}$ & $1^{\mathrm{a}}$ & $2^{\mathrm{a}}$ & $1^{\mathrm{a}}$ & $2^{\mathrm{a}}$ \\
\hline & \multicolumn{10}{|c|}{ Safra 2008/2009 } \\
\hline Cambissolo Húmico & $146 a$ & $127 \mathrm{a}$ & $143 a$ & $145 \mathrm{a}$ & $108 \mathrm{a}$ & $130 \mathrm{a}$ & $147 \mathrm{a}$ & $128 \mathrm{a}$ & $102 \mathrm{a}$ & $91 \mathrm{a}$ \\
\hline Cambissolo Háplico & $126 b$ & $116 \mathrm{a}$ & $129 b$ & $131 b$ & $107 \mathrm{a}$ & $121 \mathrm{a}$ & $123 b$ & $114 b$ & $97 \mathrm{a}$ & $98 \mathrm{a}$ \\
\hline \multirow[t]{2}{*}{$\mathrm{CV}(\%)$} & 17 & 20 & 17 & 15 & 18 & 16 & 16 & 17 & 22 & 24 \\
\hline & \multicolumn{10}{|c|}{ Safra 2009/2010 } \\
\hline Cambissolo Húmico & $140 \mathrm{a}$ & $142 \mathrm{a}$ & $159 a$ & $153 a$ & $156 \mathrm{a}$ & $158 \mathrm{a}$ & $159 \mathrm{a}$ & $158 \mathrm{a}$ & - & - \\
\hline Cambissolo Háplico & $129 b$ & $127 \mathrm{~b}$ & $144 b$ & $144 \mathrm{a}$ & $141 b$ & $143 b$ & $142 b$ & $140 \mathrm{~b}$ & - & - \\
\hline $\mathrm{CV}(\%)$ & 16 & 17 & 15 & 16 & 15 & 16 & 16 & 15 & - & - \\
\hline
\end{tabular}

${ }^{(1)}$ Médias seguidas de letras iguais na coluna não diferem entre si, pelo teste DMS, a 5\% de probabilidade. 
matéria orgânica no Cambissolo Húmico (Tabela 1), associado a seu relevo mais plano, explicam o maior armazenamento de água nesse solo. Segundo Leeuwen et al. (2009), maior quantidade de água disponível no solo aumenta o crescimento das bagas e diminui a concentração de açúcares, o que afeta a composição do vinho. O solo e as condições meteorológicas afetaram a maioria das características físico-químicas do mosto (Tabela 4), com exceção do conteúdo de taninos, para as condições meteorológicas, e o de polifenóis totais, para ambos os fatores. Já a interação entre os fatores de variação somente foi significativa no caso da acidez titulável e do pH do mosto.

As condições de solo explicaram 3\% da variação em acidez titulável, $6 \%$ no teor de sólidos solúveis e $18 \%$ no $\mathrm{pH}$ do mosto. A condição meteorológica, no entanto, foi o fator que explicou a maior parte da variação das características físico-químicas da uva (Tabela 4). Leeuwen et al. (2004) avaliaram a influência de clima, solo e cultivar em "terroir", na França, e observaram que os atributos de solo explicaram $32 \%$ da variação no teor de sólidos solúveis e 3\% da variação no $\mathrm{pH}$ do mosto, e as condições meteorológicas explicaram 15\% da variação no teor de sólidos solúveis e $73 \%$ no pH do mosto. Ubalde et al. (2010) observaram que o solo foi responsável por 30\% da variação em sólidos solúveis, enquanto o clima foi responsável por $40 \%$ da variação em sólidos solúveis, $65 \%$ na acidez titulável e 33\% no $\mathrm{pH}$ do mosto.

As uvas produzidas em Cambissolo Háplico apresentaram maior teor de sólidos solúveis e de taninos e menores valores de acidez titulável, $\mathrm{pH}$ do mosto e teor de antocianinas, em comparação ao Cambissolo Húmico (Tabela 5). O índice de polifenóis totais não diferiu entre os tratamentos.

Tabela 4. Percentagem da variância atribuída aos fatores solo, condições meteorológicas e interação, quanto às características físico-químicas e aos compostos fenólicos de uvas 'Cabernet Sauvignon'.

\begin{tabular}{lccc}
\hline Característica & Solo & Safra & Solo x Safra \\
\hline Sólidos solúveis & $6^{* *}$ & $93^{* *}$ & $1^{\mathrm{ns}}$ \\
Acidez titulável & $3^{* *}$ & $86^{* *}$ & $11^{* *}$ \\
$\mathrm{pH}$ do mosto & $18^{* *}$ & $69^{* *}$ & $13^{* *}$ \\
Polifenóis totais & $58^{\mathrm{ns}}$ & $41^{\mathrm{ns}}$ & $1^{\mathrm{ns}}$ \\
Antocianinas & $28^{* *}$ & $71^{* *}$ & $1^{\mathrm{ns}}$ \\
Taninos & $98^{* *}$ & $0^{\mathrm{ns}}$ & $2^{\mathrm{ns}}$ \\
ns Não significativo. & $\mathrm{e}^{* *}$ Significativo a 5 e $1 \%$ de probabilidade, \\
respectivamente. & & &
\end{tabular}

O teor de sólidos solúveis foi maior na safra de 2008/2009, intermediário em 2010/2011 e menor em 2009/2010 (Tabela 5). Na safra de 2008/2009, a maturação da uva ocorreu em período com menor precipitação pluvial, o que favorece o acúmulo de açúcar nas bagas (Rizzon \& Miele, 2006).

Nas safras avaliadas, não houve correlação entre o teor de sólidos solúveis e o $\mathrm{pH}$ do mosto, e nem entre a acidez titulável e $\mathrm{pH}$ do mosto, nas uvas cultivadas no dois Cambissolos (Tabela 6). No entanto, na safra 2008/2009, houve correlação negativa entre sólidos solúveis e acidez titulável, tanto no Cambissolo Húmico como no Cambissolo Háplico. Na safra 2010/2011, no Cambissolo Háplico, também houve correlação negativa entre sólidos solúveis e acidez do mosto. A ausência de correlação entre sólidos solúveis e $\mathrm{pH}$ do mosto pode ser atribuída, parcialmente, a variações das condições meteorológicas entre as safras, as quais tem maior efeito sobre o teor de sólidos solúveis do que sobre o pH do mosto. Ubalde et al. (2010) também não observaram correlação entre o teor de sólidos solúveis e o $\mathrm{pH}$ do mosto.

Tabela 5. Características físico-químicas e compostos fenólicos de uvas 'Cabernet Sauvignon', de acordo com o solo e as safras avaliadas ${ }^{(1)}$.

\begin{tabular}{|c|c|c|c|c|c|}
\hline \multirow[t]{3}{*}{ Característica } & \multicolumn{2}{|c|}{ Solo } & \multicolumn{3}{|c|}{ Safra } \\
\hline & Cambissolo & Cambissolo & 2008 & $2009 /$ & $2010 /$ \\
\hline & Húmico & Háplico & 2009 & 2010 & 2011 \\
\hline Sólido solúveis $\left({ }^{\circ} \mathrm{Brix}\right)$ & $18,4 \mathrm{~b}$ & $19,4 \mathrm{a}$ & $20,9 \mathrm{~A}$ & $16,1 \mathrm{C}$ & $19,8 \mathrm{~B}$ \\
\hline Acidez titulável $\left(\mathrm{meq} \mathrm{L} \mathrm{L}^{-1}\right)$ & $166 \mathrm{a}$ & $156 \mathrm{~b}$ & $126 \mathrm{C}$ & $186 \mathrm{~A}$ & $170 \mathrm{~B}$ \\
\hline $\mathrm{pH}$ do mosto & $3,2 \mathrm{a}$ & $3,0 \mathrm{~b}$ & $3,1 \mathrm{~B}$ & $3,3 \mathrm{~A}$ & $2,9 \mathrm{C}$ \\
\hline Polifenóis totais & $43,8 \mathrm{a}$ & $46,4 \mathrm{a}$ & $44,0 \mathrm{~A}$ & - & $46,2 \mathrm{~A}$ \\
\hline Antocianinas $\left(\mathrm{mg} \mathrm{L}^{-1}\right)$ & $803 a$ & $725 b$ & $701 \mathrm{~B}$ & - & $827 \mathrm{~A}$ \\
\hline Taninos $\left(\mathrm{mg} \mathrm{g}^{-1}\right)$ & $1,4 \mathrm{~b}$ & $1,6 \mathrm{a}$ & $1,5 \mathrm{~A}$ & - & $1,5 \mathrm{~A}$ \\
\hline
\end{tabular}

Tabela 6. Correlação entre características físico químicas das bagas de uva 'Cabernet Sauvignon', em Cambissolo Húmico e em Cambissolo Háplico.

\begin{tabular}{|c|c|c|c|c|c|c|}
\hline \multirow[t]{3}{*}{ Característica } & \multicolumn{3}{|c|}{ Cambissolo Húmico } & \multicolumn{3}{|c|}{ Cambissolo Háplico } \\
\hline & 2008/ & 2009/ & $2010 /$ & 2008/ & $2009 /$ & $2010 /$ \\
\hline & 2009 & 2010 & 2011 & 2009 & 2010 & 2011 \\
\hline & \multicolumn{6}{|c|}{ Sólidos solúveis } \\
\hline Acidez titulável & $-0,33^{*}$ & ns & ns & $-0,50^{*}$ & ns & $-0,62^{* *}$ \\
\hline \multirow[t]{2}{*}{$\mathrm{pH}$ do mosto } & ns & ns & ns & ns & ns & ns \\
\hline & \multicolumn{6}{|c|}{ Acidez titulável } \\
\hline \multirow[t]{2}{*}{$\mathrm{pH}$ do mosto } & ns & ns & $\mathrm{ns}$ & ns & ns & $\mathrm{ns}$ \\
\hline & \multicolumn{6}{|c|}{ Taninos } \\
\hline Antocianinas & ns & - & $-0,35$ & ns & - & $-0,51$ \\
\hline
\end{tabular}

Pesq. agropec. bras., Brasília, v.48, n.1, p.97-104, jan. 2013 DOI: 10.1590/S0100-204X2013000100013 
Na safra 2010/2011, o teor de taninos correlacionouse negativamente ao teor de antocianinas, em ambos os solos. Esta correlação negativa pode ser explicada pela dinâmica diferente entre os teores de taninos e antocianinas, durante o amadurecimento da uva. Segundo Blouin \& Guimberteau (2004), durante a fase da maturação, o conteúdo de antocianinas aumenta regularmente, ao contrário do de taninos, que atinge um máximo antes da mudança de cor das bagas e diminui até a colheita. Ubalde et al. (2010) também observaram correlação negativa entre teor de taninos e de antocianinas.

A disponibilidade de água foi a principal diferença entre os dois solos (Tabela 3) e, provavelmente, a variável com maior efeito sobre a composição da uva (Castellarin et al., 2007; Lebon et al., 2006; Leeuwen et al., 2009). Segundo Lebon et al. (2006), em solos com maior disponibilidade hídrica ocorre competição entre a parte aérea e os frutos pelos sólidos solúveis, com consequente redução do seu teor nas bagas.

Quanto às condições meteorológicas, observou-se maior amplitude térmica na safra 2008/2009 (de 8, $8^{\circ} \mathrm{em}$ março e de $9,6^{\circ}$ em abril), em comparação a 2009/2010 (de $8,2^{\circ}$ em março e de $7,4^{\circ}$ em abril) e a 2010/2011 (de $8,7^{\circ} \mathrm{em}$ março e de $8,6^{\circ} \mathrm{em}$ abril) (Tabela 2). Segundo Rosier (2006), a concentração de açúcares nas bagas é favorecida por dias com maior amplitude térmica, que proporcionam menores perdas por respiração e menor crescimento da parte aérea.

A acidez e o $\mathrm{pH}$ do mosto variaram entre as safras (Tabela 5). O pH do mosto foi maior em 2009/2010, safra com maior precipitação pluvial, e menor em 2010/2011. Em 2009/2010, os solos também tiveram efeito na acidez titulável, possivelmente relacionado a diferenças da drenagem e do armazenamento de água (Leeuwen et al., 2004). A acidez titulável afeta o pH do mosto, o que é importante no processo de fermentação malolática, para estabilização dos microrganismos e para a definição da cor do vinho (Brighenti et al., 2011).

No Cambissolo Húmico, foi observada correlação positiva entre o $\mathrm{pH}$ do mosto e o teor de $\mathrm{K}$ no solo $(\mathrm{r}=0,41, \mathrm{n}=37, \mathrm{p}<0,05)$. Rizzon \& Miele (2002) argumentam que a maior concentração de $\mathrm{K}$ na baga acarreta a salificação do ácido tartárico, o que provoca a elevação do $\mathrm{pH}$ do mosto e a diminuição da acidez titulável. Rizzon \& Miele (2006) trabalharam com a variedade Isabel, em diferentes Municípios da Serra
Gaúcha, e também observaram correlação positiva entre $\mathrm{pH}$ do mosto e teor de $\mathrm{K}$ no solo.

Observou-se efeito do solo e das condições meteorológicas no teor de antocianinas, e efeito do solo no teor de taninos (Tabela 4). Não houve efeito do solo nem das condições meteorológicas sobre o índice de polifenóis totais, diferentemente do observado em dois solos da Espanha por Ubalde et al. (2010), que relataram que o solo explicou $24 \%$ e o clima $64 \%$ da variação dos teores de polifenóis totais, e por Chavarria et al. (2011) que observaram que, quando a disponibilidade hídrica no solo foi menor, o teor de polifenóis totais nas uvas aumentou.

O fator solo representou $28 \%$ e o fator condições meteorológicas $71 \%$ da variação no teor de antocianinas. Leeuwen et al. (2004) trabalharam com a cultivar Cabernet Sauvignon e também observaram efeito de clima e solo sobre teor de antocianinas. As uvas cultivadas em Cambissolo Húmico tiveram os maiores teores de antocianinas, em comparação às uvas cultivadas em Cambissolo Háplico (Tabela 5).

$\mathrm{Na}$ safra 2008/2009, em Cambissolo Húmico, observou-se correlação negativa entre o teor de antocianinas das uvas e os teores de $\mathrm{Ca}^{2+}(\mathrm{r}=-0,46$,

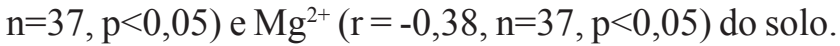
Em Cambissolo Háplico, houve correlação do teor de antocianinas apenas com o teor de $\mathrm{Ca}^{2+}(\mathrm{r}=-0,33$, $\mathrm{n}=37, \mathrm{p}<0,05$ ). Fregoni (2005) também observou relação negativa entre o teor de antocianinas e o teor de Ca no solo. Segundo Vitrac et al. (2000), a sacarose modula a biossíntese de antocianinas das células em Vitis vinifera, e o $\mathrm{Ca}^{2+}$ age como inibidor na indução da biossíntese de antocianinas pelo açúcar.

Quanto às condições meteorológicas, o maior teor de antocianinas foi observado na safra 2010/2011 (Tabela 5), na qual ocorreu menor temperatura máxima média na fase de maturação da uva (março a abril), em comparação à safra 2008/2009 (Tabela 2). O aumento das temperaturas diurnas, durante $\mathrm{o}$ período de maturação, associado à alta insolação, tem relação com a redução do teor de antocianinas (Leeuwen et al., 2004). Isso explica o maior teor de antocianinas observado na safra 2010/2011. Leeuwen et al. (2004) constataram que o teor de antocianinas é afetado pelo clima, com efeito negativo das altas temperaturas sobre o acúmulo de antocianinas nas bagas. Ubalde et al. (2010) constataram que o teor de antocianinas é dependente das condições meteorológicas $(92 \%$ da 
variação total) e que o maior teor de antocianinas nas bagas ocorreu no ano com menor precipitação pluvial e menor temperatura diurna. Falcão et al. (2008) verificaram que o teor de antocianinas é afetado pelo clima, com maior teor em ano de menor precipitação pluvial no período de mudança de cor das bagas, até a colheita.

O fator solo explicou $6 \%$ da variação nos teores de taninos, ao passo que o fator condições meteorológicas e a interação entre os fatores não foram significativos (Tabela 4). O Cambissolo Háplico proporcionou maior teor de taninos na uva (Tabela 5). Leeuwen et al. (2004) e Chavarria et al. (2011) também observaram maior teor de taninos em bagas de uva proveniente de solo com menor profundidade efetiva, em que a infiltração e drenagem da água são retardadas. Ubalde et al. (2010) observaram que os teores de taninos são afetados principalmente pelo clima (65\%), com maior teor em ano com maior temperatura média, e pelo solo $(9 \%)$, em que menor infiltração e drenagem favorecem o acúmulo de taninos nas bagas.

\section{Conclusões}

1. As condições meteorológicas e o tipo de solo afetam as características físico-químicas da uva 'Cabernet Sauvignon', com exceção do teor de polifenóis totais, e o efeito das condições meteorológicas é mais pronunciado do que o efeito de solo.

2. As uvas produzidas em Cambissolo Háplico apresentam maiores teores de sólidos solúveis e taninos e menores valores de acidez titulável, $\mathrm{pH}$ do mosto e teor de antocianinas do que as produzidas em Cambissolo Húmico.

3. A menor precipitação pluvial e a maior amplitude térmica das safras favorecem o acúmulo de sólidos solúveis na uva 'Cabernet Sauvignon', enquanto a maior precipitação favorece o aumento da acidez do mosto.

4. Os teores de $\mathrm{Ca}$ e $\mathrm{Mg}$ do solo correlacionamse negativamente com os teores de antocianinas nas uvas 'Cabernet Sauvignon', e o teor de K do solo correlaciona-se positivamente ao $\mathrm{pH}$ do mosto.

\section{Referências}

AMERINE, M.A.; OUGH, C.S.; GAVILAN, C.S. Análisis de vinos y mostos. Zaragoza: Acribia, 1976. 158p.

BENEZ, M.C.; CHANIN, Y.M.A.; LAUS NETO, J.A.; BRAGA, H.J.; PUNDEK, M.; MOLINARI, A.; ROSSO, R.; CARRIÃO,
S.L.; BACIC, I.L.Z. Dados e informações biofísicas da Unidade de Planejamento Regional Planalto Sul Catarinense. Florianópolis: Epagri, 2002. 76p.

BLOUIN, J.; GUIMBERTEAU, G. Maduración y madurez de la uva. Madrid: Mundi-Prensa, 2004. 151p.

BORGHEZAN, M.; GAVIOLI, O.; PIT, F.A.; SILVA, A.L. da. Comportamento vegetativo e produtivo da videira e composição da uva em São Joaquim, Santa Catarina. Pesquisa Agropecuária Brasileira, v.46, p.398-405, 2011. DOI: 10.1590/S0100204X2011000400009.

BRIGHENTI, A.F.; RUFATO, L.; KRETZSCHMAR, A.A.; SCHLEMPER, C. Desempenho vitivinícola da 'Cabernet Sauvignon' sobre diferentes porta-enxertos em região de altitude de Santa Catarina. Revista Brasileira de Fruticultura, v.33, p.96-102, 2011. DOI: 10.1590/S0100-29452011005000039.

CASTELLARIN, S.D.; MATTHEWS, M.A.; DI GASPERO, G.; GAMBETTA, G.A. Water deficits accelerate ripening and induce changes in gene expression regulating flavonoid biosynthesis in grape berries. Planta, v.227, p.101-112, 2007. DOI: 10.1007/ s00425-007-0598-8.

CHAVARRIA, G.; BERGAMASCHI, H.; SILVA, L.C. da; SANTOS, H.P. dos; MANDELLI, F.; GUERRA, C.C.; FLORES, C.A.; TONIETTO, J. Relações hídricas, rendimento e compostos fenólicos de uvas 'Cabernet Sauvignon' em três tipos de solo. Bragantia, v.70, p.481-487, 2011. DOI: 10.1590/S000687052011005000004.

DELOIRE, A.; VAUDOUR, E.; CAREY, V.; BONNARDOT, V.; VAN LEEUWEN, C. Grapevine responses to terroir: a global approach. Journal International des Sciences de la Vigne et du Vin, v.39, p.149-162, 2005.

DOWNEY, M.O.; DOKOOZLIAN, N.K.; KRSTIC, M.P. Cultural practice and environmental impacts on the flavonoid composition of grapes and wine: a review of recent research. American Journal of Enology and Viticulture, v.57, p.257-267, 2006.

EMPRESA DE PESQUISA AGROPECUÁRIA E EXTENSÃO RURAL DE SANTA CATARINA. Centro de Informações de Recursos Ambientais. Dados climáticos. Disponível em: <http:// ciram.epagri.sc.gov.br>. Acesso em: 03 dez. 2011

FALCÃO, L.D.; CHAVES, E.S.; BURIN, V.M.; FALCÃO, A.P.; GRIS, E.F.; BONIN, V.; BORDIGNON-LUIZ, M.T. Maturity of Cabernet Sauvignon berries from grapevines grown with two different training systems in a new grape growing region in Brazil. Ciencia e Investigacion Agraria, v.35, p.271-282, 2008.

FREGONI, M. Viticoltura di qualità. Verona: Phytoline, 2005. 819p.

ILAND, P.; BRUER, N.; EDWARDS, G.; WEEKS, S.; WILKES, E. Chemical analysis of grapes and wine: techniques and concepts. Australia: Campbelltown, 2004. 48p.

KUHN, G.B. Uva para processamento: produção. Brasília: Embrapa Informação Tecnológica; Bento Gonçalves: Embrapa Uva e Vinho, 2003. 134p. (Frutas do Brasil, 34).

LEEUWEN, C. van; FRIANT, P.; CHONÉ, X.; TREGOAT, O.; KOUNDOURAS, S.; DUBOURDIEU, D. Influence of climate, soil, and cultivar on terroir. American Journal of Enology and Viticulture, v.55, p.207-217, 2004. 
LEEUWEN, C. van; SEGUIN, G. The concept of terroir in viticulture. Journal of Wine Research, v.17, p.1-10, 2006.

LEEUWEN, C. van; TREGOAT, O.; CHONÉ, X.; BOIS, B.; PERNET, D.; GAUDILLÈRE, J.-P. Vine water status is a key factor in grape ripening and vintage quality for red Bordeaux wine. How can it be assessed for vineyard management purposes? Journal International des Sciences de la Vigne et du Vin, v.43, p.121-134, 2009.

LEBON, E.; PELlEGRINO, A.; LOUARN, G.; LECOEUR, J. Branch development controls leaf area dynamics in grapevine (Vitis vinifera) growing in drying soil. Annals of Botany, v.98, p.175-185, 2006. DOI: 10.1093/aob/mcl085.

LUCIANO, R.V. Variabilidade espacial e temporal de atributos do solo e sua relação com a composição da uva para vinificação no Planalto Catarinense. 2012. 147p. Tese (Doutorado) Universidade do Estado de Santa Catarina, Lages.

MORLAT, R.; BODIN, F. Characterization of viticultural terroirs using a simple field model based on soil depth - II. Validation of the grape yield and berry quality in the Anjou vineyard (France). Plant and Soil, v.281, p.55-69, 2006. DOI: 10.1007/s11104-0053769-z.

REICHARDT, K. Processos de transferência no sistema solo-planta-atmosfera. Campinas: Fundação Cargill, 1985. 445p.

REICHERT, J.M.; ALBUQUERQUE, J.A.; KAISER, D.R.; REINERT, D.J.; URACH, F.L.; CARLESSO, R. Estimation of water retention and availability in soils of Rio Grande do Sul. Revista Brasileira de Ciência do Solo, v.33, p.1547-1560, 2009. DOI: $10.1590 /$ S0100-06832009000600004.

RIBEREAU-GAYON, P.; GLORIES, Y.; MAUJEAN, A.; DUBOURDIEU, D. Traité d'oenologie. 2. Chimie du vin: stabilisiation et traitements. Paris: Dumond, 1998. v.2, 519p.

RIZZON, L.A.; MIELE, A. Avaliação da cv. Cabernet Sauvignon para elaboração de vinho tinto. Ciência e Tecnologia de Alimentos, v.22, p.192-198, 2002. DOI: 10.1590/S0101-20612002000200015.
RIZZON, L.A.; MIELE, A. Efeito da safra vitícola na composição da uva, do mosto e do vinho Isabel da Serra Gaúcha, Brasil. Ciência Rural, v.36, p.959-964, 2006. DOI: 10.1590/S010384782006000300036.

ROSIER, J.P. Vinhos de altitude: característica e potencial na produção de vinhos finos brasileiros. Informe Agropecuário, v.27, p.105-110, 2006.

SANTOS, H.G. dos; JACOMINE, P.K.T.; ANJOS, L.H.C. dos; OLIVEIRA, V.A. de; OLIVEIRA, J.B. de; COELHO, M.R.; LUMBRERAS, J.F.; CUNHA, T.J.F. (Ed.). Sistema brasileiro de classificação de solos. 2.ed. Rio de janeiro: Embrapa Solos, 2006. 306p.

TEDESCO, M.J.; GIANELLO, C.; BISSANI, C.A.; BOHNEN, H.; VOLKWEISS, S.J. Análises de solo, plantas e outros materiais. 2.ed. Porto Alegre: Universidade Federal do Rio Grande do Sul, 1995. $174 \mathrm{p}$

UBALDE, J.M.; SORT, X.; ALICIA ZAYAS, A.; POCH, R.M. Effects of soil and climatic conditions on grape ripening and wine quality of Cabernet Sauvignon. Journal of Wine Research, v.21, p.1-17, 2010. DOI: 10.1080/09571264.2010.495851.

VITRAC, X.; LARRONDE, F.; KRISA, S.; DECENDIT, A.; DEFFIEUX, G.; MÉRILLON, J.M. Sugar sensing and $\mathrm{Ca}^{2+}$-calmodulin requirement in Vitis vinifera cells producing anthocyanins. Phytochemistry, v.53, p.659-665, 2000. DOI: 10.1016/S0031-9422(99)00620-2.

ZSÓFI, Z.; GÁL, L.; SZILÁGYI, Z.; SZUCS, E.; MARSCHALL, M.; NAGY, Z.; BÁLO, B. Use of stomatal conductance and pre-dawn water potential to classify terroir for the grape variety Kékfrankos. Australian Journal of Grape and Wine Research, v.15, p.36-47, 2009. DOI: 10.1111/j.1755-0238.2008.00036.x.

ZSÓFI, Z.; TÓTH, E.; RUSJAN, D.; BÁLO, B. Terroir aspects of grape quality in a cool climate wine region: relationship between water deficit, vegetative growth and berry sugar concentration. Scientia Horticulturae, v.127, p.494-499, 2011. DOI: 10.1016/j. scienta.2010.11.014. 